\title{
A Pragmatic Study of Compliment Responses in Northern Kurmanji
}

\author{
Dilgash M. Tayib \\ College of Languages, University of Duhok, Duhok, Kurdistan Region - Iraq
}

\begin{abstract}
Compliments and compliment responses are considered as one of the most common linguistic phenomena in all languages. People use compliments and compliments responses in everyday interaction in order to make a conversation go on. However, the strategies of complimenting and responding to them may differ from one culture to another. Such strategies are realized in terms of order, frequency, formulas and responses. The study aims at investigating compliment responses in Northern Kurmanji with reference to English. It tries to find out the similarities and differences between the two languages in terms of responding to compliments syntactically, semantically and socially. The study is based on some hypotheses, the validity of which required designing a questionnaire to find out the responses used by speakers of Northern Kurmanji in different social contexts. The questionnaire consists of written discourse completion task (DCT) with four situational settings (appearance, ability, possession and character). About 80 Kurdish college students in the Department of English/ College of Humanities/ University of Duhok during the academic year 2014.2015 participated in this study. Finally, the data are analyzed using Holmes' three categories of compliment responses (accept, reject and deflect/ evade). The analysis of the data has revealed that the native speakers of Northern Kurmanji use different strategies in responding to compliments. Moreover, native speakers of Northern Kurmanji seem to be polite in their responses to compliments.
\end{abstract}

KEYWORDS : Pragmatics, Politeness, Compliments, Compliment Responses, Northern Kurmanji.

\section{INTRODUCTION}

\subsection{The Problem}

The study investigates compliment responses in Northern Kurmanji from a pragmatic point of view, taking into consideration the role of the speaker and the hearer (listener) in giving and responding to compliments. To the best of the researcher's knowledge, such a study has not been tackled yet. Moreover, the study tries to address the following questions :

a) What are the common strategies of compliment responses used by Northern Kurmanji speakers?

b) To which extent do Northern Kurmanji speakers show politeness in their responses to compliments?

c) Are Compliment responses used by Northern Kurmanji speakers considered face threatening or face saving acts?

Academic Journal of Nawroz University

(AJNU) Volume 7, No 3 (2018).

Received 19 Feb 2018;

Regular research paper : Published 20 June 2018

Corresponding author's e-mail : dilgash.tayib@gmail.com

Copyright (2018 Dilgash M. Tayib.

This is an open access article distributed under the

Creative Commons Attribution License.

\subsection{Aims of the Study}

The study aims at analyzing the different strategies used

by Northern Kurmanji speakers when responding to a compliment.

1.3 Limits of the Study

The study is limited to investigate compliment responses in Northern Kurmanji or Bahdini dialect in the city of Duhok. The participants are university students of all stages in the Department of English, College of Humanities. Moreover, it is an attempt to figure out which types of strategies are more frequent among Northern Kurmanji speakers.

\subsection{The Hypotheses}

The study hypothesizes the following:

1. Northern Kurmanji speakers use several strategies when responding to a compliment.

2. Some strategies of complement responses are more frequent than others.

3. Northern Kurmanji speakers are polite in their responses to compliments.

\subsection{Data Collection}

The data collected to achieve the purpose of this study made use of conducting a questionnaire using 80 native speakers of Northern Kurmanji, who speak Bahdini dialect fluently. The data is limited to university 
students.

\subsection{The Model}

The model adopted in this study is that of Holmes (1988). This model is believed to be universal across all languages in the world. The model is presented in detail later on page (3).

\section{LITERATURE REVIEW}

\subsection{Definition}

According to Holmes and Brown (1987 : 523), compliments are positive speech acts that express friendship and increase rapport among people. Paying appropriate compliments and identifying them accurately is an aspect of communicative competence, which may differ in a variety of ways from one culture to another. Holmes (1988 : 446) defines compliment as "a speech act which attributes credit to someone other than the speaker, usually the person addressed, for something good (possession, characteristic, skill, etc.) which is positively valued by the speaker and the hearer."

\subsection{Compliments and other Speech Acts}

People usually use a variety of positive speech acts to exchange greetings, apologies, congratulations, requests, gratitude, giving compliments, etc. Yule (2006: 118) defines a speech act briefly as "an action performed by a speaker with an utterance". Thus, when a person says : I'm sorry I didn't mean it, he is not just speaking, but he is performing the speech act of 'apologizing'.

Compliments like other speech acts such as greetings, apologies, directives, and expressions of disapproval have rich implications. However, Manes and Wolfson (1981 : 127) claim that compliments differ in many ways from other speech acts such as greetings, thanks or farewells. The first reason behind this point of view is that such speech acts are taught, whereas compliments are not. The second reason is that compliments usually have broader functions than other speech acts since they often appear as part of, or even in place of, thanks, greetings and farewells. Another reason is that compliments are expected in certain cases, yet they are not required at any definite point within an interaction. In other words, Cs may occur at the beginning of a conversation, in the middle or at the end of it. Finally, the regularity and simplicity of detecting compliments is difficult due to the complexity of the rules for formulation.

\subsection{Compliments and Politeness}

Based on Brown and Levinson's (1978) descriptions of utterances, compliments can be regarded as positive politeness devices. That is, compliments usually belittle the threat of a face threatening act by keeping the addressee's positive face and by noticing the addressee's interests. In other words, compliments function as devices to reduce the social distance and affirm the solidarity between the speaker and addressee (Brown and Levinson, 1978 cited in Holmes, 1988 : 448).
However, sometimes compliments and compliment responses may function as face threatening acts as suggested by Brown and Levinson (ibid). In other words, compliments may threaten the addressee's negative face (a person's right to act freely and not to be interrupted by others), and compliment responses may threaten the speaker's positive face (a person's need to have her or his wants to be seen and recognized by others). According to Brown and Levinson (1987: 66), compliments are said to be face threatening acts, in which the speaker indicates that he likes or would like something which belongs to the addressee. This is usually the case in cross.cultural contexts such as the Samoan (Holmes, 1986 : 487). She illustrates this point with an example from the Samoan culture as shown below :

- Complimenter : What an unusual necklace. It's beautiful.

- Recipient : Please take it. (ibid)

In the above example, the complimenter's admiration for the object (necklace) turned to an obligation on the addressee's side to give it to the complimenter. At the same time, the response puts the complimenter in an embarrassing situation since the recipient offers him/her to take the object as a gift while the complimenter was just showing his/her admiration (Holmes, 1988 : 448.449). This is what we may call intercultural miscommunication. Levinson (1988: 339) states that giving and responding to compliments is a positive politeness strategy that addresses the hearers' positive face. In fact, most of the politeness theories refer directly or indirectly to compliments as one way of being polite, friendly, and favorable. To tell somebody you are admiring his way of talking, behavior, appearance...etc, means that you want him/her feel satisfied, confident, worth of compliment, to make him feel that you want to be his/her friend.

\subsection{Previous Studies on Compliments and Compliment} Responses

Compliments have been the focus of many linguistic investigations in recent years. Previous studies on compliments have mainly focused on the following areas : formulas, topics, functions and responses.

\subsubsection{Compliment Formulaes}

Most of the previous studies on compliments, regardless of language, have proved that they are formulaic in nature. That is, there are certain lexical items and syntactic patterns that account for the majority of them. The most interesting results are those conducted by Manes and Wolfson (1981). Their work is based on the analysis of complimenting behaviour among middle class Americans. They recognized the repetitiveness of both the lexicon and the constructions and accordingly identified nine syntactic patterns that account for the majority of the structures in their data (ibid : 120.121).

1. NP is/looks (really) ADJ 
Your sweater is really nice.

2. I (really) like/love NP

I like your car.

3. PRO is (really) (a) ADJ NP

That's a good question.

4. You V (a) (really) ADJ NP

You did a great job.

5. You V NP (really) ADV

You sang that song very well.

6. You have (a) (really) ADJ

You have a beautiful voice.

7. What (a) ADJ NP!

What a pretty shirt!

8. ADJ NP!

Nice shirt!

9. Isn't NP ADJ!

Isn't she pretty!

\subsubsection{Compliment Topics}

Compliment topics are one of the major variables in the study of compliments. Holmes $(1986: 496)$ claims that in order for a speech act to be considered as a compliment, an utterance must refer to something which is highly valued by the participants and attributed to the addressee. This means that an infinite number of possible topics would serve as compliment topics. Then she argues that in spite of introducing a broad range of topics in some studies, there are very limited topics that account for the majority of compliment topics.

In her analysis of Cs in New Zealand English, Holmes (1988 : 454.455) classifies compliment topics into a few broad topics : appearance, ability or performance, possessions, and some aspects of personality or friendliness, and assumes that the first two account for the majority of her data.

1. Appearance

I like your haircut.

2. Ability/Performance

You were acting very well today.

That's an excellent performance.

3. Possession

What a lovely house!

4. Personality/Friendship

You're such a kind person.

You're a good friend.

\subsubsection{Compliment Functions}

People usually use compliments for a variety of functions and reasons. As far as communication is concerned, the function of compliment is phatic. In other words, compliments are mainly used to make the communication among the members of a society go on (Coulmas, 1981 : 13). The main function of complimenting behaviour, according to Manes and Wolfson (1981 : 130), is "to create or reinforce solidarity by expressing appreciation or approval." Wolfson (1983: 89) argues that compliments are mainly used to "grease the social wheels" and thus to serve as "social lubricants" which create or maintain rapport.

According to Hatch (1992 : 138.139), compliments serve several functions. First of all, they help to establish rapport and replace greeting as a topic of conversation. Secondly, they are used to reinforce and encourage a good performance. Thirdly, they can replace thanks as in the case when someone says good dinner to the cook. Finally, they are used to soften criticism. Meanwhile, compliments in American English mainly serve as conversation openers and indicate closings. They can occur in the beginning, middle and the end of a conversation (ibid : 137).

\subsection{Compliment Responses}

Compliment responses are one of the major variables in recent studies on compliments in different languages. In her analyzing of compliment responses in New Zealand English, Holmes (1988 : 460) classifies compliment responses into the following categories :

A) ACCEPT

1. Appreciation / agreement token

Thanks, yes

2. Agreeing utterance

I think it is nice.

3. Downgrading / qualifying utterance

It's not so bad, isn't it?

4. Return compliment

You're looking good too.

B) REJECT

1. Disagreeing utterance

I'm afraid I don't like it much.

2. Question accuracy

Is 'beautiful' the right word?

3. Challenge sincerity

You don't really mean that.

C) DEFLECT/EVADE

1. Shift credit

My mother made it.

2. Informative comment

I bought it at Maxi Mall.

3. Legitimate evasion

Context needed to illustrate

4. Request reassurance / repetition

Do you really like it?

3. ANALYSIS OF COMPLIMENT RESPONSES IN NORTHERN KURMANJI

\subsection{Population and Sample of the Study}

The population of this study composes of the students of the Department of English, College of Humanities, University of Duhok. The sample of the study consists of 80 students belonging to the four stages of the Department of English. Most of the participants speak two languages (i.e., bilinguals). They speak Kurdish as their mother tongue as well as Arabic. Their ages range from 18 to 22 years. 


\subsection{Procedures}

The study was carried out through the use of a questionnaire, a modified version of 'Discourse Completion Test' (DCT), following the work of Blum.Kulka et al. (1989) and Chen (1993). The questionnaire was administered in Kurdish and there are descriptions of 12 situations including the four topics of compliments. In each of these situations, the subject was asked to show how s/he responds to compliments. The situations describe the events that commonly take place in real life situations in Kurdish society in Kurdistan. The respondents were asked to put themselves in each situation in order to say something relevant. The researcher visited the classes at the Department of English to administer the questionnaire during the academic year (2014. 2015).

The 12 situations distributed among the participants are the following fields of compliments :

Appearance

b) Personality/ Character

c) Ability

d) Possession

\subsection{Analysis}

An analysis of compliment responses used by Northern Kurmanji speakers is carried out to identify the different strategies of compliment responses used by them. Holmes' (1988) categories of compliment response strategies, which are adapted here, have three main strategies : Accept Reject and Evade.

\subsection{Findings}

The data collected in this study consists of responses to compliments in four situations presented in the questionnaire as follows :

SITUATION ONE : APPEARANCE

1. You look great in this dress.

2. Wow! That's a beautiful watch!

3. What a nice colour! It just fits you.

SITUATION TWO : ABILITY

4. Good job! It was an impressive presentation.

5 . You played very well in this match.

6 . The food was very delicious. You are a wonderful cook!

SITUATION THREE : POSSESSION

7. Your mobile is really great.

8. What a beautiful house!

9. You have a very nice car.

SITUATION FOUR : CHARACTER

10. Thank you! You did a great favor to me.

11. Thank you! You are really kind and helpful.

12. I really appreciate your help. I will never forget it.

The results show that the respondents intended to use the three common strategies of compliment responses; accept, reject and evade. It has been detected that the most frequently used strategy among those three responses is acceptance and accounted for $85 \%$. As for the second strategy (evade/deflect), only $13 \%$ of respondents make use of it. The less frequently used strategy among Northern Kurmanji speakers is the third type (reject), and only account for $1 \%$ of responses. It is worth mentioning that some respondents used other responses which do not match any of the above mentioned strategies. These are what we may call formulaic expressions; they account for $1 \%$ of the total responses.

Table 1 The Frequency of Strategies of Compliment Responses in Northern Kurmanji

Table (1) : Frequency of Strategies

\begin{tabular}{|l|l|}
\hline Compliment Responses & $\%$ \\
\hline Accept & 85 \\
\hline Evade/ Escape & 13 \\
\hline Reject & 1 \\
\hline Other & 1 \\
\hline
\end{tabular}

\subsection{Discussion}

In their responses to compliments, Northern Kurmanji speakers use various strategies in different situations. Throughout this study, the researcher finds out that the most common patterns of compliment responses used by Northern Kurmanji speakers are : acceptance (85\%, 816 out of 960 responses), evade (13\%, 124 out of 960 responses), and reject (1\%, 15 out of 960$)$. As far as the acceptance strategy is concerned, 720 out of 816 respondents used 'appreciation/agreement token', supas (thank you) 3afiyet bit. 59 out of 816 used 'agreeing utterance', Ere tu rast dbeji (you are right). 17 of out 816 used 'downgrading', Pa basbu, xirab nebu (not bad). Finally, 18 responses of 816 made use of 'return compliments', Tuji her wesa (you too). As for the second strategy evade/defect, 50 out of 124 responses used, 'shift credit', Biraye min ya kiri (my brother has bought for me). 48 out of 124 are 'request reassurance' responses, $\mathrm{Tu}$ ji dil we dbeji? (Do you really think so?). Meanwhile, 20 of 124 of responses are 'informative comment', mane min gelek giran ya kiri (but it cost me a lot). The less used type is 'legitimate evasion', only six responses, Ye bashe bes balkuni nine (it is good but it has no balcony). The last strategy, which is the less frequent, is rejecting. Only fifteen people used this strategy and in this order : 9 of them used 'disagreeing utterance', Lawa çıye eve du sale f1 min (it is not that good, I've been using it for two years). The other six responses are 'challenge sincerity', Tu jidil nabeji! (You must be kidding me!). As we mentioned earlier, $1 \%$ of responses turn out to be 'formulaic expressions' such as Xude ji te razibit (May God bless you). Table 2 Distribution of Compliment Responses in Northern Kurmanji.

\section{Table (2) : Distribution of Compliment Responses}




\begin{tabular}{|c|c|c|}
\hline $\begin{array}{c}\text { Compliment } \\
\text { Responses }\end{array}$ & No. & $\mathbf{\%}$ \\
\hline Accept & 816 & 85 \\
\hline Evade/ Escape & 124 & 13 \\
\hline Reject & 15 & 1 \\
\hline Other & 5 & 1 \\
\hline \\
Total $960 \quad 100$
\end{tabular}

The common patterns of compliment response strategies in Northern Kurmanji are :

1. Compliment responses for appearance

a) Thanking

Supas (thanks)

b) Appreciation

Çavet te di ciwanin (your eyes are nice)

c) Returning compliment

Ya teji ya ciwane (yours is also beautiful)

2. Compliment responses for character

a) Thanking

Supas (thanks)

b) Shift credit

Ew ji kerema Xudeye (that is God's generosity)

c) Appreciation

$\mathrm{Tu}$ ji qenciya $\mathrm{xu}$ wedbeji (that's from your kindness)

3. Compliment responses for ability

a) Thanking

Supas (thanks)

b) Appreciation

3afiyet bit (bon appétit)

b) Disagreeing

Direwe, ez neye zirekim (that's not true, I am not clever)

4. Compliment responses for possession

a) Thanking

Supas, qebilke (thanks, take it)

b) Agreeing

Rast beji, cureke bashe (you are right, it's a good one)

c) Shift credit

Hevale min ya daye min (my friend gave it to

me).

Table 3 Common Compliment Topics \& Reponses used by Northern Kurmanji Speakers

Table (3) : Common Compliment Topics \& Reponses

\begin{tabular}{|c|c|c|}
\hline Topic & Response & Example \\
\hline \multirow{3}{*}{ Appearance } & Thanking & Supas \\
\hline & Appreciation & $\begin{array}{l}\text { Çavet te di } \\
\text { ciwanin }\end{array}$ \\
\hline & Returning & Ya teji ya ciwane \\
\hline \multirow{3}{*}{ Character } & Thanking & Supas \\
\hline & Shift Credit & $\begin{array}{c}\text { Ew ji kerema } \\
\text { Xudeye }\end{array}$ \\
\hline & Appreciation & $\begin{array}{c}\text { Tu ji qenciya } x u \\
\text { wedbeji }\end{array}$ \\
\hline \multirow{3}{*}{ Ability } & Thanking & Supas \\
\hline & Appreciation & 3afiyet bit \\
\hline & Disagreeing & $\begin{array}{l}\text { Direwe, ez neye } \\
\text { zirekim }\end{array}$ \\
\hline
\end{tabular}

\begin{tabular}{|c|c|c|}
\hline \multirow{4}{*}{ Procession } & Thanking & Supas \\
\cline { 2 - 3 } & Agreeing & $\begin{array}{c}\text { Rast beji, cureke } \\
\text { bashe }\end{array}$ \\
\cline { 2 - 3 } & Shift Credit & $\begin{array}{c}\text { Hevale min ya } \\
\text { daye min }\end{array}$ \\
\hline
\end{tabular}

\section{Conclusions}

The study has come up with the following conclusions : 1. Native speakers of Northern Kurmanji tend to use three strategies in their responses to compliments. These strategies are acceptance, rejection and deflection/ evasion. However, the frequency of using these strategies differs from one speaker to another. That is, the participants used these strategies in the following order : acceptance $(85 \%)$, deflection/evasion (13\%), and rejection $(1 \%)$.

2. Native speakers of Northern Kurmanji used formulaic expressions when responding to a compliment. These expressions are used as a part of daily conversation, and their use is rare. They account for $1 \%$ of the responses.

3. Native speakers of Northern Kurmanji seem to be polite in their responses to compliments. They show more awareness and they are more careful about their responses.

4. The study was limited college students. That is, they are educated people from both sexes whose ages range from 18 to 22 years. Different results may be found among uneducated people.

5.The responses of native speakers of Northern Kurmanji are considered as 'face saving acts'. i.e., they do not threat the hearer's positive face, rather they try to save his/her face.

\section{References}

1.Blum.Kulka, S., House, J., \& Kasper, G. (1989). Cross.cultural pragmatics : Requests and apologies. Norwood, NJ : Ablex.

2.Brown, P., \& Levinson, S. (1987). Politeness : Some universals in language use. Cambridge : Cambridge University Press.

3. Chen, R. (1993). Responding to compliments : A contrastive study of politeness strategies between American English and Chinese speakers. Journal of Pragmatics, 20, 49.75.

4. Coulmas, F. (Ed.). (1981). Conversational routine : Explorations in standardized communication situations and prepatterned speech. The Hague : Mouton.

5. Hatch, E. (1992). Discourse and language education. Cambridge: Cambridge University Press.

6. Holmes J. (1986). Compliment and compliment responses in New Zealand English. Anthropological Linguistics, 28, 485.508 .

7. Holmes, J. (1988). Paying compliments : A sex.preferential politeness strategy. Journal of Pragmatics, 12, 445.465.

8. Holmes, J \& Brown, D. F. (1987). Teachers and students learning about compliments. TESOL Quarterly, 
21, 523.546.

9. Levinson, S. (1988). Pragmatics. Cambridge : Cambridge University Press.

10. Manes, J. \& Wolfson, N. (1981). The Compliment

Formulae. In F. Coulmas (Ed.), Conversational routines:
Exploration in standardized communication situations and prepatterned speech (pp. 116.132). The Hague: Mouton.

11. Yule, G. (2006). The study of language (3rd ed.). Cambridge : Cambridge University Press. 